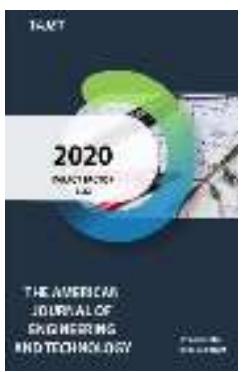

Journal Website: http://usajournalshub.c om/index,php/tajet

Copyright: Original content from this work may be used under the terms of the creative commons attributes 4.0 licence.

\section{Experimental Optimization Of Litchi Spray Pre-Cooling Process Parameters}

\author{
Chen Minglin \\ Guangdong Institute Of Modern Agricultural Equipment, Guangzhou 510640, China \\ Lv Enli \\ College Of Engineering, South China Agricultural University, Guangzhou 510642, China \\ Gan Ling \\ Corresponding Author \\ Guangdong Institute Of Modern Agricultural Equipment, Guangzhou 510640, China
}

\title{
ABSTRACT
}

Pre-cooling is an important part of the post-harvest cold chain logistics of litchi. Spray pre-cooling can quickly reduce the temperature of litchi. Mastering the best process parameters of spray pre-cooling can improve the pre-cooling efficiency. Taking the "Huaizhi" litchi as the research object, the orthogonal experiment was carried out by selecting factors such as spray temperature, spray flow, and litchi layer number, and the optimal process parameters of litchi spray precooling were obtained through range analysis and variance analysis. The results show that when the spray temperature is $5^{\circ} \mathrm{C}$, the spray flow rate is $5 \mathrm{~L} /\left(\mathrm{s} \bullet \mathrm{m}^{2}\right)$, and the number of litchi layers is 3 , the $7 / 8$ litchi pre-cooling time is shorter, the pre-cooling uniformity $\sigma$ is small, and the pre-cooling Best results.

\section{KEYWORDS}

Spray pre-cooling; temperature; flow; number of layers; orthogonal test

\section{INTRODUCTION}

Litchi is harvested in the summer of high temperature and humidity. After harvest, it is easy to be infected by pathogenic bacteria, and the peel is easy to brown and lose its commercial value. Pre-cooling can quickly cool fruits and vegetables, inhibit pathogen infection, and extend the preservation time. It is an important 
part of the cold chain logistics of agricultural products $[1,2,3]$. Spray pre-cooling is a method of cold water pre-cooling [4]; its main principle is to spray cold water on the surface of fruits and vegetables to exchange heat between fruits and vegetables and cold water, which has the advantages of high efficiency and convenient operation [5]. Litchi is small in size and hard in the skin. Spray pre-cooling is easy to pre-cool and does not damage the fruit. It is more suitable for spray pre-cooling.

Clément [6] changed the arrangement of sweet corn during pre-cooling, and studied the influence of the form of sweet corn in water on the pre-cooling time and storage quality. Elansari [7] established the date palm spray pre-cooling cooling model and studied the cooling rate of the date palm. Lu Shengping [8] studied the cooling characteristics of litchi with different pre-cooling methods and summarized the better methods of litchi pre-cooling. Lu Enli[9] studied the influence of different cold water temperature, spray flow rate, and the amount of litchi on the precooling effect, and conducted a preliminary exploration on litchi spray pre-cooling. However, few scholars comprehensively analyze the temperature, spray flow rate, and the amount of litchi spraying and pre-cooling, and obtain better spraying and precooling parameters.

To this end, this paper builds a litchi spray pre-cooling test platform, and uses the orthogonal test method to study the effects of spray temperature, spray flow and litchi amount on the cooling effect of litchi fruits, hoping to provide litchi spray pre-cooling technology and equipment The optimization provides a reference.

\section{TEST DEVICE AND METHOD}

\section{TEST DEVICE}

The spray pre-cooling device for the test is shown in Figure 1. The cold water is sprayed on the surface of the litchi through the nozzle under the suction action of the variable frequency pump and finally flows back to the cold storage box to form a cycle. The spray flow can be adjusted by changing the pressure of the variable frequency pump, and the safety valve can urgently control the opening and stopping of the nozzle. The temperature of the lychee pulp is measured by a platinum resistance PT100 made by Heraeus, Germany, with a range of -60 to $300^{\circ} \mathrm{C}$ and an accuracy of $\pm 0.15^{\circ} \mathrm{C}$.

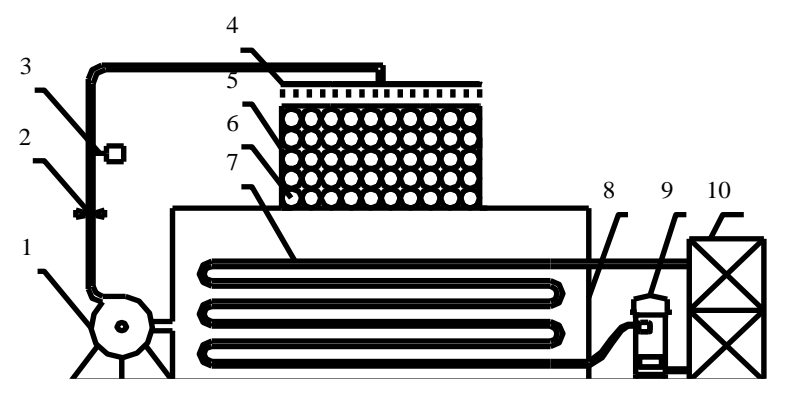

1. Frequency conversion pump

2. Pressure relief valve

3. Digital display flowmeter

4. Spray Nozzle

5. Perforated basket

6. Litchi

7. Evaporating coil

8. Ice cool storage box

9. Compressor

10. Condenser

Figure 1 Litchi spray precooling test platform

\section{TEST MATERIALS}

The litchi variety used in the experiment was "Huaizhi", with a maturity of 8-9. The lychees were transported back to the test within $3 \mathrm{~h}$ 
after picking, and the lychees with a diameter between 30 and $32 \mathrm{~mm}$ were selected as the test material.

\section{TEST METHOD}

According to the main factors and levels of litchi spray pre-cooling in literature [9], the main factors and levels in the test process are determined as follows: spray temperature $(A)$, spray flow rate (B), litchi layer number (C), as shown in the table 1 shown. The orthogonal test method was used to study the effects of spray temperature, spray flow, and litchi stacking layers on the pre-cooling effect.

Table 1 Test factors and levels

\begin{tabular}{cccc}
\hline \multirow{2}{*}{ levels } & \multicolumn{3}{c}{ factors } \\
\cline { 2 - 4 } & Spray temperature $A /{ }^{\circ} \mathrm{C}$ & Spray flow $B / \mathrm{L} \cdot \mathrm{s}^{-1} \cdot \mathrm{m}^{-2}$ & Lychee layers $C$ \\
\hline 1 & 8 & 4 & 2 \\
2 & 5 & 5 & 3 \\
3 & 2 & 6 & 4 \\
\hline
\end{tabular}

\section{EVALUATION INDICATORS}

$1 / 2,3 / 4,7 / 8$ pre-cooling time

The pre-cooling time of agricultural products is usually $1 / 2,3 / 4$, and $7 / 8$ to measure the cooling effect and rate to avoid the influence of fluid temperature $[7,10]$. In this paper, $1 / 2,3 / 4,7 / 8$ pre-cooling time is used to measure the precooling rate of litchi fruit in the middle and late stages of the pre-cooling process. The $7 / 8$ precooling time is taken as the standard for the end of pre-cooling, and the calculation formula is

$$
Z=\frac{t_{0}-t}{t_{0}-t_{\infty}}
$$

In the formula: $Z$ is a dimensionless number, taking $1 / 2,3 / 4,7 / 8$; $t$ is the temperature of litchi fruit at any time, ${ }^{\circ} \mathrm{C}$; to is the spray temperature, ${ }^{\circ} \mathrm{C}$; to is the initial temperature of litchi fruit, ${ }^{\circ} \mathrm{C}$.

Pre-cooling uniformity refers to the difference of fruit temperature at different positions in the pre-cooling process. Poor pre-cooling uniformity can easily lead to chilling injury or incomplete pre-cooling of litchi. This article uses the temperature variation coefficient of litchi to evaluate the uniformity of pre-cooling [11]. The calculation formula is

$$
\sigma=\frac{1}{t_{p}} \sqrt{\frac{1}{n-1} \sum_{i=1}^{n}\left(\mathrm{t}_{i}-t_{p}\right)^{2}}
$$

In the formula: $\sigma$ is the uniformity; tp is the average temperature of each litchi fruit, ${ }^{\circ} \mathrm{C}$; ti is the temperature of the first litchi fruit, ${ }^{\circ} \mathrm{C} ; \mathrm{n}$ is the number of measuring points. 
The American Journal of Engineering and Technology (ISSN - 2689-0984)

Published: August 19, 2020 | Pages: 45-52

2020:5. 32

Doi: https://doi.org/10.37547/tajet/Volume02Issue08-06

Orthogonal Test Results And Analysis Of Litchi Spray Pre-Cooling Process Parameters

\section{Range Analysis Of Test Results}

The three factors and three levels listed in Table 1 were tested. The test plan and results are shown in Table 2.

Table 2 Orthogonal test results and range analysis

\begin{tabular}{|c|c|c|c|c|c|}
\hline \multirow{2}{*}{$\begin{array}{c}\text { Serial } \\
\text { number }\end{array}$} & $\begin{array}{c}\text { Spray } \\
\text { temperature } \\
\mathrm{A} /{ }^{\circ} \mathrm{C}\end{array}$ & $\begin{array}{c}\text { Spray } \\
\text { flow } \\
\mathrm{B} / \mathrm{L} \cdot \mathrm{S}^{-} \\
{ }^{1} \cdot \mathrm{m}^{-2}\end{array}$ & $\begin{array}{c}\text { Lychee } \\
\text { layers C }\end{array}$ & $\begin{array}{c}\text { Spray } \\
\text { temperature } \\
\mathrm{A} /{ }^{\circ} \mathrm{C}\end{array}$ & $\sigma$ \\
\hline 1 & 1 & 1 & 1 & 8.71 & 0.080 \\
\hline 2 & 1 & 2 & 2 & 8.50 & 0.093 \\
\hline 3 & 1 & 3 & 3 & 10.25 & 0.088 \\
\hline 4 & 2 & 1 & 3 & 9.05 & 0.157 \\
\hline 5 & 2 & 2 & 1 & 9.24 & 0.131 \\
\hline 6 & 2 & 3 & 2 & 8.35 & 0.120 \\
\hline 7 & 3 & 1 & 2 & 10.33 & 0.217 \\
\hline 8 & 3 & 2 & 3 & 9.33 & 0.243 \\
\hline 9 & 3 & 3 & 1 & 9.71 & 0.277 \\
\hline$k_{11}$ & 9.15 & 9.36 & 9.22 & & \\
\hline$k_{12}$ & 8.88 & 9.02 & 9.06 & & \\
\hline$k_{13}$ & 9.79 & 9.44 & 9.54 & & \\
\hline$R_{1 j}$ & 0.91 & 0.42 & 0.48 & & \\
\hline$k_{21}$ & 0.087 & 0.151 & 0.163 & & \\
\hline$k_{22}$ & 0.136 & 0.156 & 0.143 & & \\
\hline$k_{23}$ & 0.246 & 0.162 & 0.163 & & \\
\hline$R_{2 j}$ & 0.159 & 0.011 & 0.020 & & \\
\hline & & & & & \\
\hline & & & & & \\
\hline
\end{tabular}

Note: k11, k12, k13 represent the average $7 / 8$ pre-cooling time of each level of the factor, $k 21$, k22, k23 represent the average pre-cooling uniformity $\sigma$ of each level of the factor, and the range $R$ represents the maximum value of $k$ of the same factor The difference from the minimum value.
It can be seen from Table 2 that from the $7 / 8$ pre-cooling time, the best combination is the 6th group $A_{2} B_{3} C_{3}$, that is, the spray temperature is $5^{\circ} \mathrm{C}$, the spray flow is $6 \mathrm{~L} /\left(\mathrm{s} \cdot \mathrm{m}^{2}\right)$, and the number of stacked layers of litchi fruit is 2 . The $7 / 8$ pre-cooling time of this group is 
8.35 min, which is $80.3 \%$ of the longest time group. From the pre-cooling uniformity $\sigma$, the best combination is the first group $\mathrm{A}_{1} \mathrm{~B}_{1} \mathrm{C}_{1}$, that is, the spray temperature is $8^{\circ} \mathrm{C}$, the spray flow is $4 \mathrm{~L} /\left(\mathrm{s} \cdot \mathrm{m}^{2}\right)$, and the number of litchi fruit stacks is 2, this group is pre-cooled The uniformity $\sigma$ is 0.08 , which is $28.9 \%$ of the group with the most uneven temperature distribution of litchi fruits.

It can be seen from Figure 2 that when evaluating the $7 / 8$ pre-cooling time index, the second level $\left(5^{\circ} \mathrm{C}\right)$ of the spray temperature $(A)$ is better than the other levels $\left(8,2^{\circ} \mathrm{C}\right)$; the spray flow rate $(B)$ is The second level $\left(5 \mathrm{~L} \cdot \mathrm{S}^{-}\right.$

$\left.{ }^{1} \cdot \mathrm{m}^{-2}\right)$ is better than other levels $\left(4,6 \mathrm{~L} \cdot \mathrm{s}^{-1} \cdot \mathrm{m}^{-2}\right)$; the second level (3) of litchi layer (C) is excellent At other levels $(2,4)$. The optimal combination $\mathrm{A}_{2} \mathrm{~B}_{2} \mathrm{C}_{2}$ is obtained, that is, the spray temperature is $5^{\circ} \mathrm{C}$, the spray flow rate is $5 \mathrm{~L} /\left(\mathrm{s} \cdot \mathrm{m}^{2}\right)$, and the number of litchi layers is 3 . From the value of the range $R_{1 j}$, it can be concluded that the most important factor affecting the $7 / 8$ pre-cooling time is the spray temperature (A), and the primary and secondary order is $A, C, B$.



\section{Figure 2 The relationship between $7 / 8$ pre-cooling time and various influencing factors}

It can be seen from Figure 3 that when evaluating the index of pre-cooling uniformity $\sigma$, the first level of spray temperature $(A)\left(8^{\circ} \mathrm{C}\right)$ is better than other levels $\left(5,2^{\circ} \mathrm{C}\right)$; the first level of spray flow (B) One level $\left(4 \mathrm{~L}^{\mathrm{s}-1} \cdot \mathrm{m}^{-2}\right)$ is better than other levels $\left(5,6 \mathrm{~L} \cdot \mathrm{s}^{-1} \cdot \mathrm{m}^{-2}\right)$; the second level (3) of litchi layers (C) is better Other levels $(2,4)$. The optimal combination $\mathrm{A}_{1} \mathrm{~B}_{1} \mathrm{C}_{2}$ is obtained, that is, the spray temperature is $8^{\circ} \mathrm{C}$, the spray flow rate is $4 \mathrm{~L} /\left(\mathrm{s} \cdot \mathrm{m}^{2}\right)$, and the number of litchi layers is 3 . From the value of the range $R_{2 j}$, it can be concluded that the most important factor affecting the pre-cooling uniformity $\sigma$ is the spray temperature $(A)$, and the primary and secondary order is A, C, B. 


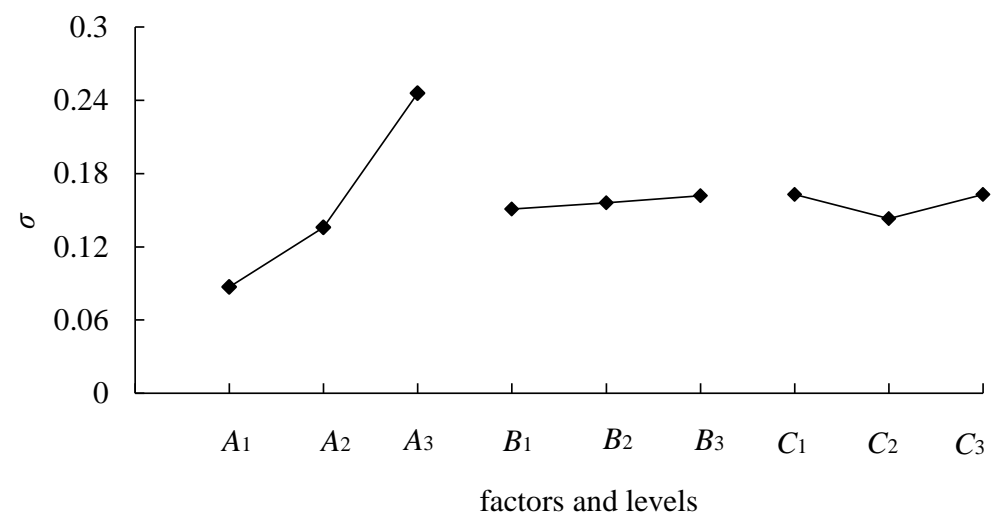

Figure 3 The relationship between the uniformity of pre-cooling and various influencing

\section{Analysis Of Variance Of Test Results}

Table 3 shows the results of variance analysis of the $7 / 8$ precooling time and precooling uniformity $\sigma$ of the orthogonal experiment. It can be seen from the table that the spray precooling process parameters have no significant influence on the $7 / 8$ pre-cooling time $(P>0.05)$, and the degree of influence of the 3 factors on the $7 / 8$ pre-cooling time is $A, C, B$, that is, the spray temperature has the greatest influence, followed by the litchi layer, and the spray flow is the smallest. The spray temperature is the most important factor affecting the $7 / 8$ precooling time. From the Newton cooling formula $q=A h \Delta t$, it can be seen that the heat dissipation of litchi is proportional to the difference between the temperature of the litchi fruit and the temperature of the cold water. The lower the spray temperature, the heat dissipation per unit time The more the quantity, the faster the cooling speed, and the shorter the $7 / 8$ pre-cooling time. In addition, there is a certain limit to the influence of the spray flow rate and the number of litchi layers. Increasing the spray flow rate is mainly to increase the $A$ value in the Newtonian cooling formula, but the $A$ value is limited by the total surface area of the litchi. When the spray flow increases to a certain value, cold water The contact with the surface of litchi is sufficient, and the $A$ value is increased by increasing the spray flow rate, thereby increasing the convective heat transfer rate is limited. The fewer layers of litchi, the larger the contact area between litchi and cold water, and the faster the convection heat transfer.

It can be seen from Table 3 that the spray temperature $(A)$ significantly $(P<0.05)$ affects the uniformity of litchi fruit pre-cooling, and the spray flow rate (B) and the number of litchi layers $(C)$ have no significant influence on the uniformity of litchi fruit pre-cooling ( $P>0.05$ ). The degree of influence of the three factors on the pre-cooling uniformity $\sigma$ from large to small is $A, C, B$, which is the same as the influence on the $7 / 8$ pre-cooling time. The spray temperature $(A)$ is the main factor affecting the uniformity of the litchi pre-cooling. The lower the pre-cooling temperature, the worse the temperature uniformity. Therefore, there is a certain limit to increase the pre-cooling rate by reducing the spray temperature; as the level of litchi increases (C), the contact area between the lychee fruit and the cold water is reduced. The cold water flows down from the 
gap between the upper layer of lychee, and uneven contact with the lower layer of lychee fruit, which is easy to cause uneven precooling; the smaller the contact area between the cold water and the lychee fruit in the spray flow, the insufficient pre-cooling, The temperature is uneven.

Table 3 Analysis of variance of orthogonal test results

\begin{tabular}{|c|c|c|c|c|c|c|}
\hline $\begin{array}{c}\text { Evaluation } \\
\text { index }\end{array}$ & $\begin{array}{c}\text { Variance } \\
\text { source }\end{array}$ & $\begin{array}{c}\text { Sum of } \\
\text { squares }\end{array}$ & $\begin{array}{c}\text { Degree } \\
\text { of } \\
\text { freedom }\end{array}$ & $\begin{array}{c}\text { Mean } \\
\text { square }\end{array}$ & F ratio & $\begin{array}{c}\text { Significance } \\
\text { level }\end{array}$ \\
\hline \multirow{2}{*}{$\begin{array}{c}7 / 8 \text { pre- } \\
\text { cooling } \\
\text { time /min }\end{array}$} & $\mathrm{A}$ & 1.308 & 2 & 0.654 & 0.617 & 0.618 \\
\cline { 2 - 7 } & $\mathrm{B}$ & 0.292 & 2 & 0.146 & 0.138 & 0.879 \\
\cline { 2 - 7 } & error & 2.119 & 2 & 1.060 & & 0.854 \\
\hline \multirow{3}{*}{$\sigma$} & $\mathrm{A}$ & 0.040 & 2 & 0.02 & 23.166 & 0.041 \\
\cline { 2 - 7 } & $\mathrm{B}$ & $1.6 \times 10^{-4}$ & 2 & $8.1 \times 10^{-5}$ & 0.095 & 0.914 \\
\cline { 2 - 7 } & $\mathrm{C}$ & $7.5 \times 10^{-4}$ & 2 & $3.7 \times 10^{-4}$ & 0.437 & 0.696 \\
\cline { 2 - 7 } & error & 0.002 & 2 & $8.5 \times 10^{-4}$ & & \\
\hline
\end{tabular}

The range analysis and the variance analysis have the same law. The influence of the three factors on the $7 / 8$ pre-cooling time and the pre-cooling uniformity $\sigma$ is $A, C, B$ in order. The optimal storage temperature for litchi is 3 to $5^{\circ} \mathrm{C}$, and low temperatures below $3^{\circ} \mathrm{C}$ can easily cause chilling injury to the fruit [12]. The selling temperature of litchi is usually in the range of 5 to $13^{\circ} \mathrm{C}[13]$. When the spraying temperature is $2^{\circ} \mathrm{C}$, the pre-cooling is uneven, and the lychee fruit is easily frostbited. When the spraying temperature is $8^{\circ} \mathrm{C}$, the precooling rate is slow, and the final pre-cooling temperature cannot meet the needs of litchi storage, so the spraying temperature is $5^{\circ} \mathrm{C}$. It has a faster pre-cooling rate and better precooling uniformity. When the number of layers is 3 , the $7 / 8$ pre-cooling time and pre-cooling uniformity $\sigma$ of litchi fruit are both smaller than the other two levels, and the optimal number of pre-cooling layers is 3. The pre-cooling uniformity $\sigma$ of litchi with different spray flow rates is between 0.15 and 0.162 , which has little effect on the uniformity of litchi fruits. Therefore, the spray flow rate is selected as 5 under the premise of giving priority to the effect on the $7 / 8$ pre-cooling time $L /\left(\mathrm{s} \cdot \mathrm{m}^{2}\right)$ not only guarantees the pre-cooling efficiency but also good pre-cooling uniformity. Therefore, comprehensively considering the optimal combination of litchi spray pre-cooling process parameters is $A_{2} B_{2} C_{2}$, that is, the spray temperature is $5^{\circ} \mathrm{C}$, the spray flow rate is 5 $\mathrm{L} /\left(\mathrm{s} \cdot \mathrm{m}^{2}\right)$, and the number of litchi layers is 3 .

\section{CONCLUSION}

A litchi spray pre-cooling test platform was built, and the effects of spray temperature, spray flow rate, and litchi layer number on the spray pre-cooling characteristics of litchi fruit were studied through orthogonal experiments. The test results showed that: 3 factors affect $7 / 8$ The influence degree of precooling time and pre-cooling uniformity $\sigma$ is spray temperature $(A)$, litchi layer number $(C)$, spray flow rate $(B)$, and the optimal parameter 
combination is $A_{2} B_{2} C_{2}$, that is, the spray temperature is $5^{\circ} \mathrm{C}$, The spray flow rate is 5 $\mathrm{L} /\left(\mathrm{s} \cdot \mathrm{m}^{2}\right)$, and the number of litchi layers is 3 .

\section{FUNDING}

This work is supported by the Guangdong Science and Technology Planning Project (2017B020206005), the "Innovative and Strong School Project" of South China Agricultural University, the independent innovation capability improvement project, the 2020 Guangdong Rural Revitalization Strategy Special Project, and the 2021 Guangdong Rural Revitalization Strategy Special Project Support.

\section{REFERENCES}

1. Han Jiawei, Zhao Chunjiang, Yang Xinting, et al. Effect of air-inflow velocity on cooling efficiency during forced-air precooling of apples[J]. Transactions of the Chinese Society for Agricultural Machinery, 2015, 46(11): 280-289.

2. Azam $M$ M, Eissa $A$ H A, Hassan A $H$. Monitoring of change in cantaloupe fruit quality under pre-cooling and storage treatments[J]. Journal of Food Processing \& Technology, 2015, 6(12): 527.

3. Han Q, Gao H, Chen H, et al. Precooling and ozone treatments affects postharvest quality of black mulberry (Morus nigra) fruits[J]. Food Chemistry, 2017, 221: 19471953.

4. Becker B R, Fricke B A. Hydrocooling time estimation methods[J]. International Communications in Heat and Mass Transfer, 2002, 29(2): 165-174.

5. Góral D, Kluza F, Kozłowicz K. Assessment of heat transfer and mass change during fruits and vegetables impingement precooling[J]. International Journal of Food Engineering, 2014, 10(1): 183-189.

6. Clément Vigneault, Goyette B, Yvan Gariépy, et al. Effect of ear orientations on hydrocooling performance and quality of sweet corn[J]. Postharvest Biology \& Technology, 2007, 43(3): 351-357.

7. Elansari A M. Hydrocooling rates of Barhee dates at the Khalal stage[J]. Postharvest Biology \& Technology, 2008, 48(3): 402407.

8. Lü Shengping, Lü Enli, Lu Huazhong, et al. Cooling characteristics of different precooling methods for litchi[J].Journal of South China Agricultural University, 2015, 36(3):114-119.

9. Lü Enli, Chen Minglin, Liu Yanhua, et al. Effects of different spray precooling parameters on cooling characteristics of litchi[J]. Transactions of the Chinese Society of Agricultural Engineering (Transactions of the CSAE), 2018, 34(24): 292-298.

10. Liu Meiyu, Cui Jianyun, Ren Fazheng, et al. Forced-air precooling conditions of eggs[J]. Transactions of the Chinese Society for Agricultural Machinery, 2010, 41(8): 135-139.

11. Yang Peizhi, Hu Xia, Liao Gang. Effect of air supply temperature on cooling efficiency for pressure precooling of apples[J]. Journal of Thermal Science and Technology, 2017, 16(5): 381-386.

12. Wei-Rong H U , Zhao-Qi Z, Yue-Ming J , et al. Study on the Parameter of IceTemperature Storage in Litchi (Litchi chinensis Sonn.)[J]. Scientia Agricultura Sincia, 2005, 38(4):797-802.

13. Ru-He X, Guang-Hai L, Yi-Feng $Z$, et al. Influence on litchi quality in different logistics conditions[J]. Journal of Guangzhou University(Natural Science Edition), 2013, 12(1):81-83. 